\title{
B7-H3 expression in breast cancer and upregulation of VEGF through gene silence
}

This article was published in the following Dove Press journal:

OncoTargets and Therapy

29 October 2014

Number of times this article has been viewed

\author{
Jing Sun' \\ Yun-Di Guo' \\ Xiao-Ning $\mathrm{Li}^{\prime}$ \\ Yang-Qin Zhang' \\ Li Gu' \\ Ping-Ping $\mathrm{Wu}^{\prime}$ \\ Guang-Hui Bai \\ Yang Xiao'
}

'Suzhou Health College, Jiangsu Suzhou, People's Republic of China;

${ }^{2}$ The Fourth Hospital of Suzhou, Jiangsu Suzhou, People's Republic of China
Correspondence: Jing Sun Institute of Medical Technology, 28 Kehua Road, Suzhou Health

College, Suzhou, Jiangsu 215009 ,

People's Republic of China

Tel +86 51262690192

Fax +86 5I262690083

Email jsun@szhct.edu.cn

Yang Xiao

Institute of Medical Technology,

28 Kehua Road, Suzhou Health

College, Suzhou, Jiangsu 2I 5009,

People's Republic of China

Tel +8651262690192

Fax +8651262690083

Email yxiao@szhct.edu.cn
Abstract: B7-H3, a novel member of the B7 family, was previously known as a regulatory ligand regulating T-cell-mediated immune response, and in recent years it was found to take a significant role in various cancers. In some tumor types, high expression of B7-H3 had been linked to a poor prognosis, whereas in other cancers the opposite effect had been observed. The precise role of B7-H3 in tumor immunity is unclear, and further investigations are needed. In the present study, we studied the expression of B7-H3 in the pathologic specimens of 221 patients treated for breast cancer by immunohistochemistry. Strong B7-H3 expression was found in cancer tissues from $80.55 \%$ patients, and B7-H3 expression had a negative relation with vascular endothelial growth factor (VEGF) expression, microvascular density for CD34, and tumor size. Furthermore, through lipopolysaccharide-mediated delivery of stable short hairpin ribonucleic acid we observed that silencing of B7-H3 could increase the transcription and secreting of VEGF in breast cancer cell line MCF-7. In summary, the present study demonstrated that B7-H3 suppressed tumor growth through inhibiting VEGF expression. These results increased knowledge of the nonimmunological role of B7-H3 protein and provided novel insights into great biological functions and a putative therapeutic target in breast cancer.

Keywords: breast cancer, B7-H3, vascular endothelial growth factor

\section{Introduction}

B7-H3 (CD276), a new member of the B7 family, was cloned from a dendritic cell deoxyribonucleic acid (DNA) library in 2001 and has a low expression in many normal lymphoid and peripheral tissues. ${ }^{1}$ But many reports reveal that B7-H3 is elevated in many cancers: eg, lung cancer, ${ }^{2,3}$ prostate cancer, ${ }^{4,5}$ ovarian carcinoma, ${ }^{6}$ colorectal carcinoma, ${ }^{7}$ pancreatic cancer, ${ }^{8,9}$ and gastric cancer. ${ }^{10}$ In these studies, B7-H3 was demonstrated with controversial functions. Ample evidence indicated that higher levels of B7-H3 expression in tumors were detrimental to effective immunity and had been associated with poor prognosis, tumor development, and progression. ${ }^{11-14}$ However, there was also a steady flow of reports that suggested that B7-H3 might also have antitumor effects under certain circumstances through exerting a protective role from natural killer (NK)-medicated lysis or CD8+ cytolytic T-cells. ${ }^{15-18}$ In these types of cancer associated with B7-H3, breast cancer was seldom refereed, so the clinical significance of B7-H3 expression in breast cancer needs to be elucidated.

Breast cancer is the most frequently diagnosed cancer and the leading cause of cancer death among women around the world, accounting for $23 \%$ of the new cancer cases and $14 \%$ of the cancer deaths in $2008 .{ }^{19}$ In the past 10 years, breast cancer incidence has increased by $20 \%-30 \%$ in the People's Republic of China's urban 
registries. ${ }^{20}$ Angiogenesis is a pivotal natural process of new blood vessel formation and plays an essential role in breast cancer development and metastasis. ${ }^{21}$ Vascular endothelial growth factor (VEGF) is essential for the development of the neovasculature during tumor formation and stimulates tumor metastasis, proliferation, invasion, and endothelial cell migration. The expression of VEGF directly contributes to the poor prognosis and a tendency for metastasis in solid tumors such as breast cancer. ${ }^{22}$ The elevated expression of VEGF can be associated with shorter relapse-free survival in early-stage breast cancer patients. ${ }^{23}$ In addition, the level of VEGF expression is regulated by many factors, including many transcriptional activators and some cytokines.

In the present study, we carried out an immunohistochemistry study to characterize B7-H3 in breast cancer, and B7-H3 expression was found to have a negative correlation with tumor size. In addition, we have found a negative relationship between B7-H3 and VEGF expression or microvascular density (MVD) for CD34, suggesting the role of B7-H3 in angiogenesis. Furthermore, we used in vitro assays to investigate the role of $\mathrm{B} 7-\mathrm{H} 3$ in inhibiting the secreting of VEGF.

\section{Materials and methods}

\section{Patients}

Patients undergoing surgery for breast cancer from January 2009 to December 2010 in the Department of General Surgery of the Fourth Hospital of Suzhou, Jiangsu, People's Republic of China, had their tumor specimens banked after giving their informed consent. Cancer tissues from 221 patients were used in the present study and none of the patients received preoperative chemotherapy or radiotherapy before the surgery. All 221 cases had hematoxylin and eosin staining performed and final pathologic diagnoses were confirmed. The patients' pathological reports were recorded. Their clinical parameters are shown in Table 1. Two hundred and twenty-one patients with benign breast diseases who were also subjected to appropriate breast surgery were used as a control group. Prior to commencing this study, approval from the Ethics Review Board of the hospital was granted and informed consent was obtained from each tissue donor.

\section{Cell culture and antibody}

Breast cancer cell line MCF-7 was purchased from Shanghai Cell Biology Institutes, Chinese Academy of Science (Shanghai, People's Republic of China). MCF-7 cells were maintained in a complete medium of Roswell Park Memorial Institute (RPMI) 1640 (Thermo Fisher Scientific, Waltham, MA, USA) containing 10\% fetal bovine serum
Table I Correlations between B7-H3 expression and clinicopathological factors in breast cancer

\begin{tabular}{|c|c|c|c|}
\hline \multirow[t]{2}{*}{ Factor } & \multicolumn{2}{|c|}{ No of patients (\%) } & \multirow[t]{2}{*}{$P$} \\
\hline & $\begin{array}{l}\text { Low expression } \\
\text { of B7-H3 }\end{array}$ & $\begin{array}{l}\text { High expression } \\
\text { of B7-H3 }\end{array}$ & \\
\hline \multicolumn{4}{|l|}{ Age (y) } \\
\hline Median & 56.4 & 56.6 & \\
\hline Range & $28-84$ & $56-89$ & \\
\hline \multicolumn{4}{|l|}{ Subtype } \\
\hline Luminal A & $6(5.40 \%)$ & I (0.90\%) & \\
\hline Luminal B & $52(46.85 \%)$ & $58(52.72 \%)$ & \\
\hline HER2(+) & $36(32.43 \%)$ & $40(36.36 \%)$ & \\
\hline Triple negative & $17(15.45 \%)$ & II (9.9l\%) & 0.1450 \\
\hline \multicolumn{4}{|l|}{ Tumor region } \\
\hline Left breast & $56(25.34 \%)$ & $55(24.89 \%)$ & \\
\hline Right breast & $5 \mathrm{I}(23.08 \%)$ & $53(23.98 \%)$ & \\
\hline Bitemporal breast & $4(0.02 \%)$ & $2(0.01 \%)$ & \\
\hline \multicolumn{4}{|l|}{ Tumor size } \\
\hline$<3 \mathrm{~cm}$ & $68(30.77 \%)$ & $85(38.46 \%)$ & \\
\hline$\geq 3 \mathrm{~cm}$ & $43(19.46 \%)$ & 25 (11.31\%) & 0.0099 \\
\hline \multicolumn{4}{|c|}{ Lymph node metastasis } \\
\hline Negative & $61(30.34 \%)$ & $58(28.86 \%)$ & \\
\hline Positive & 40 (19.90\%) & $42(20.90 \%)$ & 0.7296 \\
\hline \multicolumn{4}{|l|}{ ER } \\
\hline Negative & $49(22.17 \%)$ & 45 (20.36\%) & \\
\hline Positive & $62(28.05 \%)$ & $65(29.41 \%)$ & 0.6267 \\
\hline \multicolumn{4}{|l|}{ PR } \\
\hline Negative & $67(30.32 \%)$ & $63(28.50 \%)$ & \\
\hline Positive & 44 (19.9l\%) & 47 (2I.27\%) & 0.6410 \\
\hline \multicolumn{4}{|l|}{ HER2 } \\
\hline Negative & 20 (9.05\%) & 35 (15.84\%) & \\
\hline Positive & 91 (4I.I8\%) & 75 (33.94\%) & 0.0177 \\
\hline
\end{tabular}

Abbreviations: HER2, human epidermal growth factor receptor; ER, estrogen receptor; PR, progesterone receptor; No, number; $y$, years.

(FBS) (HyClone, Logan, UT, USA) and cultured at $37^{\circ} \mathrm{C}$ in a humidified incubator supplemented with $5 \% \mathrm{CO}_{2}$. Antibodies used in this study included goat anti-B7-H3 (Catalog No BAF1027; R\&D Systems; Minneapolis, MN, USA), mouse anti-VEGF monoclonal antibody (Clone No VG1; Maixin Bio, Fuzhou, People's Republic of China), and mouse antiCD34 monoclonal antibody (Clone No QBEnd/10; Maixin Bio). Horseradish peroxidase-labeled goat antimouse/ rabbit purchased from Maixin Bio was used as the secondary antibody.

\section{Construction of tissue microarray}

Tissue microarrays were constructed. Area-specialized histopathologists identified and marked formalin-fixed paraffin-embedded tissue blocks containing tumor tissue on hematoxylin and eosin-stained slides. Two replicate $0.2 \mathrm{~mm}$ cores from the center and periphery of the tumors were taken and arrayed into a recipient paraffin block using a tissue 
puncher/arrayer (Beecher Instruments, Silver Spring, MD, USA). Four micron sections of the tissue array block were cut and placed on Superfrost Plus slides for immunohistochemical staining.

\section{Immunohistochemistry}

Immunohistochemical staining of B7-H3, VEGF, and CD34 was performed using the Maixin $\mathrm{Bio}^{\mathrm{TM}}$ method according to the manufacturer's instructions. Sections $(3 \mu \mathrm{m})$ were mounted on Superfrost Plus slides, deparaffinized, rehydrated, incubated with Mayer's hematoxylin solution, and heated at $100^{\circ} \mathrm{C}$ for 30 minutes in citrate solution or ethylenediaminetetraacetic acid solution when needed. The sections were incubated with antiB7-H3 $(10 \mu \mathrm{g} / \mathrm{mL})$ and anti-VEGF $(10 \mu \mathrm{g} / \mathrm{mL})$ and further processed using the EnVision Peroxidase Detection System with horseradish peroxidase-labeled secondary antibodies. The sections were counterstained with Gill's haematoxylin, and coverslips were applied. Irrelevant isotype-matched antibodies were used to control for nonspecific staining.

\section{Evaluation of immunohistochemical staining}

Two independent observers who were blinded to the clinicopathological parameters of patients examined the immunohistochemically stained sections. B7-H3 and VEGF expression data were limited to tumors with sufficient tissue for immunohistochemical evaluation. A semiquantitative scoring scheme based on the distribution of positive tumor cells and the staining intensity was used to evaluate the expression of B7-H3 and VEGF. The distribution score, which is an estimate of the percentage of positively stained cells, was multiplied by an intensity factor that ranged from 0 (weak positive, staining intensity just exceeding background) to 3 (strong positive, dark brown staining obvious on macroscopic inspection of the slide). For analysis, the B7-H3 or VEGF immunostaining intensities were classified as follows. The sections scored as Grade 0 and Grade 1 were defined as the low-expression group, and other sections scored as Grade 2 and Grade 3 were defined as the high-expression group.

To determine the MVD, tumor sections stained with CD34 antibody were examined under a Nikon E400 brightfield microscope (Nikon, Tokyo, Japan), and images were captured using a digital camera (DU100; Nikon) at $\times 200$ objective lens magnification. For each tumor section, three to five fields with the greatest density of positively stained vessels (hot spots) were evaluated, irrespective of the tumor region. MVD was defined as the number of positively stained vessels per high-power field. Sections with MVD value $\leq 60$ were defined as the low group and $>60$ were defined as the high-expression group.

\section{Short interfering ribonucleic acid}

MCF-7 was grown in RPMI medium supplemented with $10 \%$ FBS and 1\% penicillin/streptomycin. Three stealth ribonucleic acid (RNA) interference (RNAi) and two control RNAi were obtained from Invitrogen Life Technologies algorithms based against the Sequence Accession No AK075549 from GenBank. Stealth RNAi was pooled in equimolar amounts and used at a working concentration of $10 \mu \mathrm{M}$ to knock down B7-H3 expression. Control RNAi was also pooled in equimolar amounts and used at a working concentration of $10 \mu \mathrm{M}$. MCF-7 was transfected with RNAi using Lipofectamine ${ }^{\text {TM }} 2000$ (Invitrogen) and replated for 48 hours before use. To evaluate the effect of transfection, real-time polymerase chain reaction (PCR) was performed to analyze the $\mathrm{B} 7-\mathrm{H} 3$ expression, and the primers were 5'-GGCTGTCTGTCTGTCTCATTG-3' and 5'-TCCATCATCTTCTTTGCTGTCA-3'. At the same time, the supernatants were harvested and frozen at $-80^{\circ} \mathrm{C}$ until assayed for the secretion of VEGF.

\section{RNA isolation and real-time PCR}

MCF-7 cells were collected and centrifugated at $500 \times g$ after treating with B7-H3 RNAi. The supernatant was removed and the cell pellet was resuspended in $350 \mu \mathrm{L}$ RNeasy lysis (RLT) buffer (Qiagen, Basel, Switzerland) and stored at $-20^{\circ} \mathrm{C}$ until RNA isolation. Total RNA was isolated from the cells using an RNeasy Mini Kit (Qiagen, Germany). Genomic DNA was removed from total RNA before complementary deoxyribonucleic acid (cDNA) synthesis using the RNase-Free DNase Set for DNase digestion during RNA purification. RNA was stored at $-80^{\circ} \mathrm{C}$. First-strand cDNA synthesis was performed for each RNA sample using a PrimeScript First cDNA synthesis kit (Takara Bio Inc., Shiga, Japan). Random hexamers were used to prime cDNA synthesis. Messenger RNA (mRNA) expression data were collected and quantitatively analyzed on a Bio-Rad iCycler CFX96. The glyceraldehyde 3-phosphate dehydrogenase (GAPDH) gene was used as an endogenous control, and all values were expressed as folds relative to the expression of GAPDH. Samples for real-time PCR were reverse transcribed with an Oligo(dT) primer using a PrimeScript First cDNA synthesis kit (Takara). The following primers for $\mathrm{B} 7-\mathrm{H} 3$ were used: forward primer 5'-CTTGTTCGATGTTCACAGCG-3' and reverse primer 5'-GCCGTAGAGCTGTCTTGGATC-3'. VEGF forward primer 


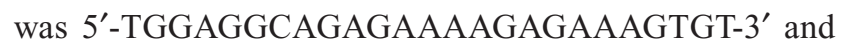
reverse primer 5'-AAGAGAGCAAGAGAGAGCAAGAT-3'. For amplification of B7-H3 and VEGF, $1 \mu \mathrm{L}$ cDNA was added to SYBR Green PCR Master Mix (Takara Bio Inc.) containing $400 \mathrm{nM}$ forward and reverse primers. PCR was performed using the following thermal settings: one cycle each of 5 minutes at $95^{\circ} \mathrm{C}, 30$ seconds at $94^{\circ} \mathrm{C}, 30$ seconds at $60^{\circ} \mathrm{C}$, and 30 seconds at $72^{\circ} \mathrm{C}$, repeat $39-49$ cycles, 10 minutes at $72^{\circ} \mathrm{C}$, and $4^{\circ} \mathrm{C}$ thereafter. Relative mRNA expression was calculated with the comparative cycle threshold method. As a calibrator, the sample with the median cycle threshold value was used and set to $100 \%$.

\section{VEGF measurement}

Enzyme-linked immunosorbent assays (ELISA) were performed on culture media $(400 \mu \mathrm{L})$ collected from the MCF-7 breast cancer cells or short interfering RNA (siRNA) treated cells. Protein levels of VEGF were measured using an ELISA kit for human VEGF (Multisciences, Hangzhou, People's Republic of China), according to the manufacturer's instructions. Optical density was read at $450 \mathrm{~nm}$ and quantified using an ELISA reader equipped with specialized software (Thermo Fisher Scientific, Waltham, MA, USA).

\section{Statistical analysis}

All data were expressed as mean \pm standard deviation. Statistical analysis was performed with the Student's $t$-test and analysis of variance. Correlations were evaluated by the Pearson correlation test. Values with $P<0.05$ were considered statistically significant.

\section{Results}

\section{The overexpression of B7-H3}

\section{in breast cancer tissues}

To assess the expression diversity of B7-H3 in breast cancer and normal breast tissues, immunohistochemistry analysis was performed and revealed that B7-H3 expression was present in 14 cases of 85 normal tissues (16.48\%) and 178 of 221 breast cancer tissues $(80.55 \%)$. The data are shown in Figure 1. Through the results of immunohistochemistry, we could observe that $\mathrm{B} 7-\mathrm{H} 3$ was predominant in the membrane and cytoplasm of tumor cells.

\section{The correlation of B7- $\mathrm{H} 3$ expression with patients' clinical parameters}

We analyzed $\mathrm{B} 7-\mathrm{H} 3$ expression in breast cancer tissues and found that its expression had a negative correlation with patients' tumor size $(P=0.0099)$, suggesting that $\mathrm{B} 7-\mathrm{H} 3$ is
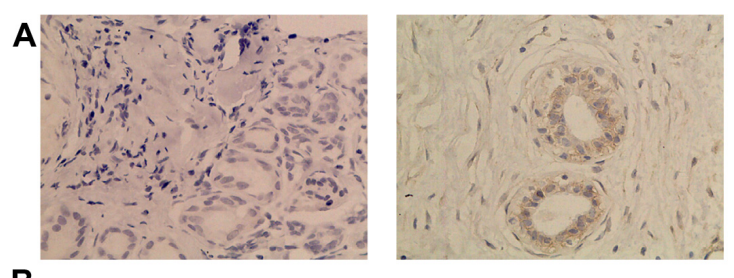

B
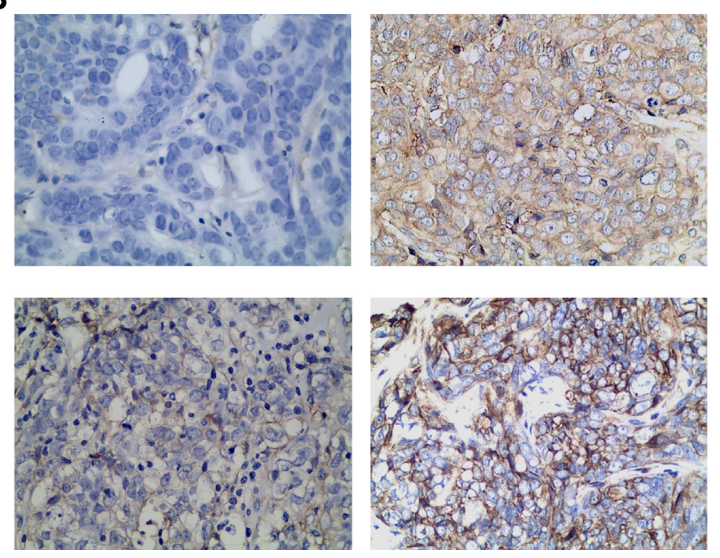

Figure I B7- $\mathrm{H} 3$ expression in breast tissues

Notes: (A) Normal breast tissue immunohistochemical microarray of B7-H3: (left) negative, (right) weak positive. (B) Breast cancer tissue microarray immunohistochemical staining of B7-H3: (top left) negative, (top right) weak positive, (bottom left) moderate positive, (bottom right) strong positive.

involved in cancer progression. B7-H3 expression levels, however, did not correlate to other clinicopathological parameters such as sex, age, tumor location, nodal metastasis, and distant metastasis (Table 1).

\section{The expression of VEGF and MVD in breast cancer and its correlation with B7-H3 expression}

We also detected and found the expression of VEGF in breast cancer tumor tissues (Figure 2) and in surrounding
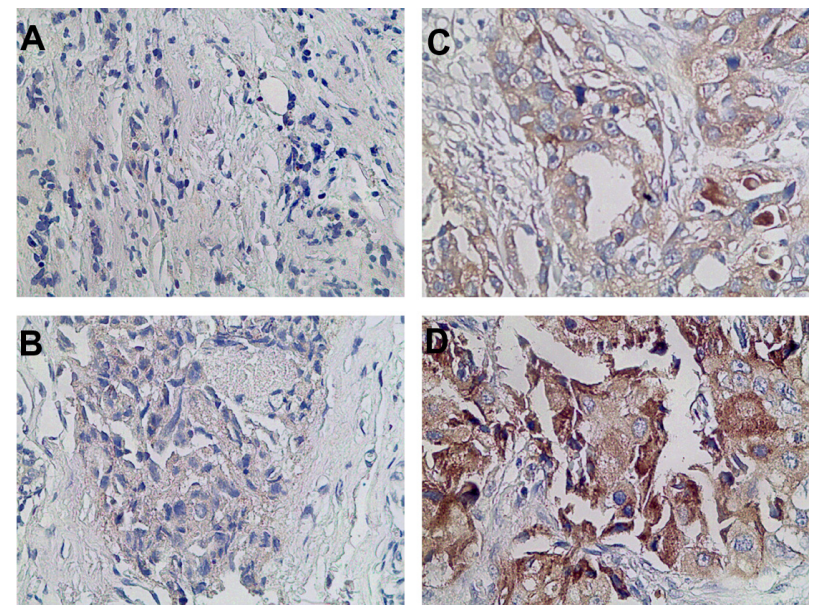

Figure 2 Breast cancer tissue microarray immunohistochemical staining of vascular endothelial growth factor.

Notes: (A) negative, (B) weak positive, (C) moderate positive, (D) strong positive. 
Table 2 Correlation between VEGF and B7-H3 expression in breast cancer

\begin{tabular}{|c|c|c|c|c|c|c|c|c|c|c|}
\hline & \multicolumn{5}{|c|}{ VEGF expression (ratios \%) } & \multicolumn{5}{|c|}{ MVD for CD34 } \\
\hline & Cases & Low, n(\%) & High, n(\%) & $\chi^{2}$ & $P$ & Cases & Low, n(\%) & High, $n(\%)$ & $\chi^{2}$ & $P$ \\
\hline \multicolumn{11}{|c|}{ B7-H3 expression } \\
\hline Low expression & 111 & $40(18.10 \%)$ & 71 (32.13\%) & & & 45 & 18 (21.43\%) & $27(32.14 \%)$ & & \\
\hline High expression & 110 & $59(26.70 \%)$ & $5 \mathrm{I}(23.08 \%)$ & 6.921 & $0.009 *$ & 39 & $24(28.57 \%)$ & $15(17.86 \%)$ & $3.877^{*}$ & $0.049 *$ \\
\hline Total & 221 & & & & & 84 & & & & \\
\hline
\end{tabular}

Note: $* P<0.05$.

Abbreviations: VEGF; vascular endothelial growth factor; MVD, microvascular density.

tissue, but it was absent or barely detectable in healthy breast tissue of patients with benign breast disease. The expression of VEGF was distributed mostly in the cytoplasm of the tumor cells, but also their expression was detected in the cytoplasm of the tumor vessel endothelial cells. To research the B7-H3 signal in regulating the tumor angiogenesis, we also assessed whether there was an association between B7-H3 expression and VEGF or MVD. Indeed, the expression of VEGF and MVD had a significant correlation with $\mathrm{B} 7-\mathrm{H} 3(P=0.0085)$. If the tumor cell expressed higher B7-H3, low VEGF and low MVD were presented (Table 2).

\section{Silence of $\mathrm{B} 7-\mathrm{H} 3$ promotes VEGF secretion in vitro}

We used siRNA transfection to decrease B7-H3 expression to determine whether downregulation of $\mathrm{B} 7-\mathrm{H} 3$ enhances VEGF secreting. After B7-H3 RNA transfection in MCF-7 cells, B7-H3 mRNA expression was downregulated significantly after 48 hours (Figure $3 \mathrm{~A}$ and B). Then we detected the expression of VEGF in MCF-7 through real-time PCR, and ELISA in MCF-7 cell line or its serum. VEGF mRNA level was increased by approximately $100 \% 48$ hours after transfection of B7-H3-specific siRNA in MCF-7 cells (Figure 4A and $B)$. At the same time, we analyzed the secretion of VEGF in the serum of MCF-7 cells through ELISA and we found that downregulation of B7-H3 also led to enhanced expression of VEGF protein (Figure 5).
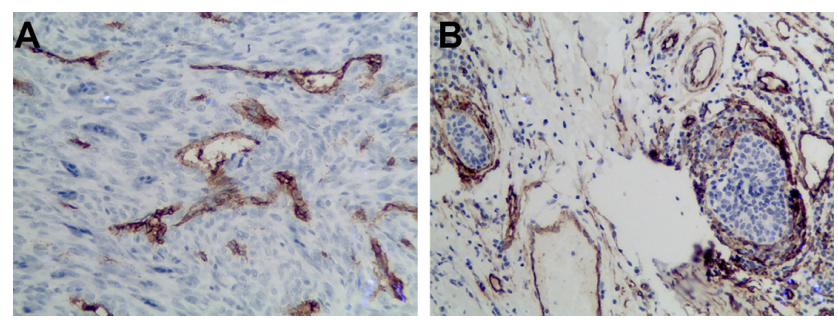

Figure 3 Representative tissues from breast cancer with staining for CD34. Note: (A) Low microvascular density and (B) high microvascular density.

\section{Discussion}

B7-H3, a new member of the B7 family, was found and cloned from dendritic cells by Chapoval et $\mathrm{al}^{24}$ in 2001 . This transmembrane glycoprotein was previously known as an immunoregulatory molecule and was presented on T-cells, NK cells, and antigen presenting cells. However, many researchers had observed that B7-H3 expressions were not limited to immune cells. Osteoblasts, ${ }^{25}$ fibroblasts, fibroblast-like synoviocytes, ${ }^{26}$ and epithelial cells ${ }^{27}$ could present B7-H3 protein. This broad expression pattern suggests that $\mathrm{B} 7-\mathrm{H} 3$ could have more diverse immunological and probably nonimmunological functions. In recent studies, B7-H3 was found highly expressed in a variety of different human cancers ${ }^{28}$ including gastric cancer, ${ }^{29}$ colorectal cancer, ${ }^{7}$ pancreatic cancer, ${ }^{5}$ ovarian cancer, and prostate carcinoma. ${ }^{30,31}$ In the present study, through immunohistochemistry analysis, we have shown that B7-H3 is highly expressed in breast cancer cells. Increased B7-H3 expression was found in $80.55 \%$ of all 221 breast cancer patients compared with $16.48 \%$ in normal breast tissues. High expression of $\mathrm{B} 7-\mathrm{H} 3$ in breast cancer has the consistent results of $\mathrm{B} 7-\mathrm{H} 3$ expression in other solid tumors.
A

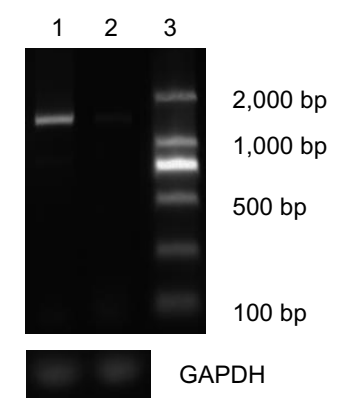

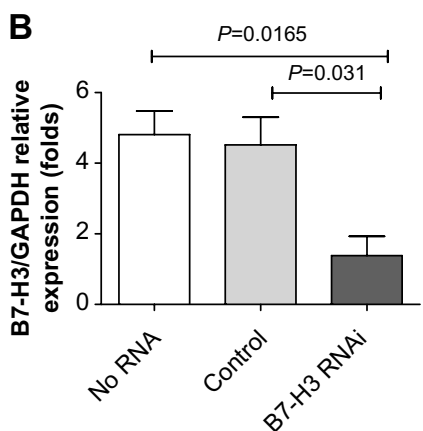

Figure 4 Knockdown efficiency of B7-H3 by siRNA in MCF-7 cells.

Notes: (A) B7-H3 mRNA expression was measured by RT-PCR. Lane I: Cells were treated with siRNA of control. Lane 2: Cells were treated with siRNA of B7-H3 for 48 hours. Lane 3: Marker DL2000. (B) Expression level of B7-H3 mRNA was measured by means of real-time PCR 48 hours after siRNA transfection. Values are mean \pm standard deviation of triplicate samples.

Abbreviations: siRNA, short interfering ribonucleic acid; mRNA, messenger ribonucleic acid; RT-PCR, reverse-transcription polymerase chain reaction; GAPDH, glyceraldehyde 3-phosphate dehydrogenase; bp, base pair; PCR, polymerase chain reaction; RNA, ribonucleic acid; RNAi, ribonucleic acid interference. 
A

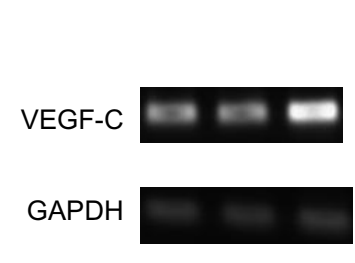

B

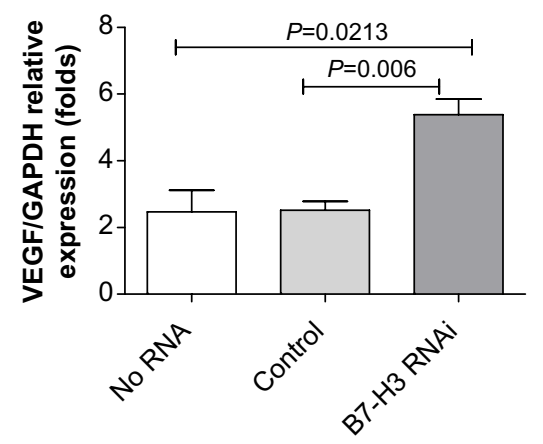

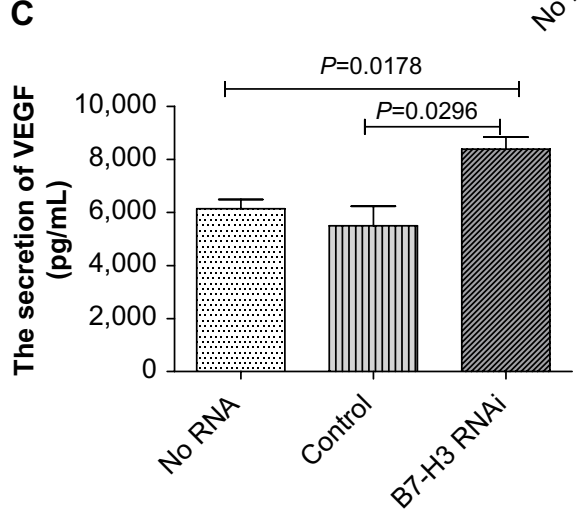

Figure 5 Effects of B7-H3 on the expression of VEGF in MCF-7 cells.

Notes: (A) Expression level of VEGF-C mRNA was measured by RT-PCR. (B) Expression level of VEGF-C mRNA was measured by means of real-time PCR for 48 hours. (C) The secretion of VEGF in serum of MCF-7 cell line after siRNA transfection.

Abbreviations: VEGF, vascular endothelial growth factor; mRNA, messenger ribonucleic acid; RT-PCR, reverse-transcription polymerase chain reaction; siRNA, short interfering ribonucleic acid; GAPDH, glyceraldehyde 3-phosphate dehydrogenase; RNA, ribonucleic acid; RNAi, ribonucleic acid interference.

In some tumor types, high expression of B7-H3 has been linked to a poor prognosis, whereas in other cancers the opposite effect has been observed, so we need to investigate the precise role of $\mathrm{B} 7-\mathrm{H} 3$ in tumor immunity and in nonimmunological systems. Through analyzing the expression of B7-H3 in breast cancer cells and various clinical parameters, we observed a significant association between B7-H3 and tumor size or human epidermal growth factor receptor 2 expression. We are unable to establish a relationship between B7-H3 and survival in breast cancer because of the lack of long-term follow-up; however, our data indicate that B7-H3 expression was negatively associated with adverse clinical features of human epidermal growth factor receptor 2. These results were inconsistent with the poor prognosis of higher B7-H3 expression in some types of tumors such as colorectal carcinoma, ${ }^{7}$ non-small-cell lung cancer, ${ }^{32}$ and prostate cancer. ${ }^{14}$ In addition, they were also inconsistent with a report of $\mathrm{B} 7-\mathrm{H} 3 \mathrm{mRNA}$ expression in primary breast cancer in 2010, which found B7-H3 mRNA level was correlated with increasing tumor size, American Joint Committee on Cancer stage, and lymphovascular invasion..$^{33}$ However, our data were in accord with the B7-H3 immunologic function regarding the regulation of T-cell responses, which was demonstrated by several in vitro and in vivo experiments. ${ }^{9,10,34}$ The latter experimental and clinical data about B7-H3 provided several explanations for these seemingly conflicting data. The first one is that there were additional receptors besides triggering receptor expressed on myeloid cell-like transcript 2 reported in $2008,{ }^{35}$ which might take the opposite effect in the immunological or nonimmunological systems. The second explanation for the inconclusive data on the functional role of B7-H3 was the existence of varying isoforms of human B7-H3, including 2IgB7-H3 and 4IgB7-H3, which were evolved divergent functions in immune responses through binding to different receptors. ${ }^{36}$ The last possible explanation comprises the different expression level of B7-H3 on tumor cells, which could be of relevance for the different immunological and nonimmunological functions. So, in the complex tumor microenvironment, co-stimulatory molecule B7-H3 may interact with several possible existing receptors for different affinities and therefore may exert different functions based on its expression level.

A lot of research has reported that VEGF serves as a key angiogenic factor in a wide range of human cancers and has a pivotal role in the metastasis of solid tumors. ${ }^{37,38}$ In addition, VEGF had been one of the targets in the current antiangiogenic therapies for quite some time. In the present study, we found a significant association between the expression 
of B7-H3 and tumor size, so we presumed that there was a correlation between B7-H3 and VEGF. Our further immunohistochemical analysis indicated that strong intensity for B7-H3 could significantly relate to low expression of VEGF and low MVD in tumor cells. Additionally, through transient siRNA transfection, we observed that silencing of B7-H3 in MCF-7 cell line increased the cytokine of VEGF secretion.

\section{Conclusion}

In this paper we demonstrated for the first time the association between $\mathrm{B} 7-\mathrm{H} 3$ expression and VEGF in breast cancer. Furthermore, downregulation of B7-H3 could stimulate VEGF mRNA and protein expression. In addition, MVD in breast cancer tissue was observed to be correlated to B7-H3 expression. These results suggest that B7-H3 might play an independent role in tumor angiogenesis. Our findings provide novel insight into the function of B7-H3 and encourage researchers to seek new receptors of this protein.

\section{Acknowledgments}

This work was supported by grants from the National Natural Science Foundation of China (No 31100626), the National Natural Science Foundation of Jiangsu Province (No BK2011320), and the development of science and technology plan projects of Suzhou (No SYSD2012070).

\section{Author contributions}

Jing Sun had full access to all data in this study and takes responsibility for the integrity of the data and the accuracy of the data analysis. Jing Sun and Yundi Guo conceived the study and participated in the design of the study and manuscript editing. Yundi Guo, Xiao-Ning Li, Yang-Qin Zhang, and $\mathrm{Li} \mathrm{Gu}$ participated in the experiments of construction of tissue microarray and immunohistochemistry. PingPing Wu took part in the cell biology experiments. Dr Bai provided the breast tissue in the operation. Jing Sun takes responsibility for the acquisition of data and analysis and interpretation of data. All authors contributed toward data analysis, revising the paper and agree to be accountable for all aspects of the work.

\section{Disclosure}

The authors report no conflicts of interest in this work.

\section{References}

1. Sun M, Richards S, Prasad DV, Mai XM, Rudensky A, Dong C. Characterization of mouse and human B7-H3 genes. J Immunol. 2002;168(12):6294-6297.
2. Sun Y, Liu J, Gao P, Wang Y, Liu C. Expression of Ig-like transcript 4 inhibitory receptor in human non-small cell lung cancer. Chest. 2008;134(4):783-788.

3. Sun Y, Wang Y, Zhao J, et al. B7-H3 and B7-H4 expression in nonsmall-cell lung cancer. Lung Cancer. 2006;53(2):143-151.

4. Chavin G, Sheinin Y, Crispen PL, et al. Expression of immunosuppresive B7-H3 ligand by hormone-treated prostate cancer tumors and metastases. Clin Cancer Res. 2009;15(6):2174-2180.

5. Lehmann BD, Paine MS, Brooks AM, et al. Senescence-associated exosome release from human prostate cancer cells. Cancer Res. 2008;68(19):7864-7871.

6. Zang X, Sullivan PS, Soslow RA, et al. Tumor associated endothelial expression of B7-H3 predicts survival in ovarian carcinomas. Mod Pathol. 2010;23(8):1104-1112.

7. Sun J, Chen LJ, Zhang GB, et al. Clinical significance and regulation of the costimulatory molecule B7-H3 in human colorectal carcinoma. Cancer Immunol Immunother. 2011;59(8):1163-1171.

8. Yamato I, Sho M, Nomi T, et al. Clinical importance of B7-H3 expression in human pancreatic cancer. Br J Cancer. 2009;101(10):1709-1716.

9. Loos M, Hedderich DM, Ottenhausen M, et al. Expression of the costimulatory molecule $\mathrm{B} 7-\mathrm{H} 3$ is associated with prolonged survival in human pancreatic cancer. BMC Cancer. 2009;9:463.

10. Wu CP, Jiang JT, Tan M, et al. Relationship between co-stimulatory molecule B7-H3 expression and gastric carcinoma histology and prognosis. World J Gastroenterol. 2006;12(3):457-459.

11. Brunner A, Hinterholzer S, Riss P, Heinze G, Brustmann H. Immunoexpression of B7-H3 in endometrial cancer: relation to tumor T-cell infiltration and prognosis. Gynecol Oncol. 2012;124(1):105-111.

12. Sun J, Mao Y, Zhang YQ, et al. Clinical significance of the induction of macrophage differentiation by the costimulatory molecule B7-H3 in human non-small cell lung cancer. Oncol Lett. 2013;6(5): 1253-1260.

13. Zhao J, Lei T, Xu C, et al. MicroRNA-187, down-regulated in clear cell renal cell carcinoma and associated with lower survival, inhibits cell growth and migration though targeting B7-H3. Biochem Biophys Res Commun. 2013;438(2):439-444.

14. Zang X, Thompson RH, Al-Ahmadie HA, et al. B7-H3 and B7x are highly expressed in human prostate cancer and associated with disease spread and poor outcome. Proc Natl Acad Sci U S A. 2007;104(49): 19458-19463.

15. Lupu CM, Eisenbach C, Lupu AD, et al. Adenoviral B7-H3 therapy induces tumor specific immune responses and reduces secondary metastasis in a murine model of colon cancer. Oncol Rep. 2007;18(3): 745-748.

16. Sun X, Vale M, Leung E, Kanwar JR, Gupta R, Krissansen GW. Mouse B7-H3 induces antitumor immunity. Gene Ther. 2003;10(20): $1728-1734$.

17. Castriconi R, Dondero A, Augugliaro R, et al. Identification of 4Ig$\mathrm{B} 7-\mathrm{H} 3$ as a neuroblastoma-associated molecule that exerts a protective role from an NK cell-mediated lysis. Proc Natl Acad Sci U S A. 2004;101(34):12640-12645.

18. Luo L, Chapoval AI, Flies DB, et al. B7-H3 enhances tumor immunity in vivo by costimulating rapid clonal expansion of antigen-specific CD8+ cytolytic T cells. J Immunol. 2004;173(9):5445-5450.

19. Jemal A, Bray F, Center MM, Ferlay J, Ward E, Forman D. Global cancer statistics. CA Cancer J Clin. 2011;61(2):69-90.

20. Porter P. "Westernizing" women's risks? Breast cancer in lower-income countries. N Engl J Med. 2008;358(3):213-216.

21. Carmeliet P, Jain RK. Angiogenesis in cancer and other diseases. Nature. 2000;407(6801):249-257.

22. Hicklin DJ, Ellis LM. Role of the vascular endothelial growth factor pathway in tumor growth and angiogenesis. J Clin Oncol. 2005;23(5): 1011-1027.

23. Relf M, LeJeune S, Scott PA, et al. Expression of the angiogenic factors vascular endothelial cell growth factor, acidic and basic fibroblast growth factor, tumor growth factor beta-1, platelet-derived endothelial cell growth factor, placenta growth factor, and pleiotrophin in human primary breast cancer and its relation to angiogenesis. Cancer Res. 1997;57(5):963-969. 
24. Chapoval AI, Ni J, Lau JS, et al. B7-H3: a costimulatory molecule for T cell activation and IFN-gamma production. Nat Immunol. 2001;2(3): 269-274.

25. Xu L, Zhang G, Zhou Y, et al. Stimulation of B7-H3 (CD276) directs the differentiation of human marrow stromal cells to osteoblasts. Immunobiology. 2011;216(12):1311-1317.

26. Tran CN, Thacker SG, Louie DM, et al. Interactions of T cells with fibroblast-like synoviocytes: role of the B7 family costimulatory ligand B7-H3. J Immunol. 2008;180(5):2989-2998.

27. Calabro L, Sigalotti L, Fonsatti E, et al. Expression and regulation of B7-H3 immunoregulatory receptor, in human mesothelial and mesothelioma cells: immunotherapeutic implications. J Cell Physiol. 2011;226(10):2595-2600.

28. Chen YW, Tekle C, Fodstad O. The immunoregulatory protein human $\mathrm{B} 7 \mathrm{H} 3$ is a tumor-associated antigen that regulates tumor cell migration and invasion. Curr Cancer Drug Targets. 2008;8(5):404- 413.

29. Arigami T, Uenosono Y, Hirata M, Yanagita S, Ishigami S, Natsugoe S. B7-H3 expression in gastric cancer: a novel molecular blood marker for detecting circulating tumor cells. Cancer Sci. 2011;102(5): 1019-1024.

30. Parker AS, Heckman MG, Sheinin Y, et al. Evaluation of B7-H3 expression as a biomarker of biochemical recurrence after salvage radiation therapy for recurrent prostate cancer. Int J Radiat Oncol Biol Phys. 2011;79(5):1343-1349.
31. Wei X, Zhang G, Yuan H, et al. Detection and quantitation of soluble B7-H3 in expressed prostatic secretions: a novel marker in patients with chronic prostatitis. J Urol. 2011;185(2): 532-537.

32. Zhang G, Xu Y, Lu X, et al. Diagnosis value of serum B7-H3 expression in non-small cell lung cancer. Lung Cancer. 2009;66(2):245-249.

33. Arigami T, Narita N, Mizuno R, et al. B7-h3 ligand expression by primary breast cancer and associated with regional nodal metastasis. Ann Surg. 2010;252(6):1044-1051.

34. Wang L, Fraser CC, Kikly K, et al. B7-H3 promotes acute and chronic allograft rejection. Eur J Immunol. 2005;35(2):428-438.

35. Hashiguchi M, Kobori H, Ritprajak P, Kamimura Y, Kozono H, Azuma M. Triggering receptor expressed on myeloid cell-like transcript 2 (TLT-2) is a counter-receptor for B7-H3 and enhances T cell responses. Proc Natl Acad Sci U S A. 2008;105(30):10495-10500.

36. Sun J, Fu F, Gu W, et al. Origination of new immunological functions in the costimulatory molecule B7-H3: the role of exon duplication in evolution of the immune system. PloS One. 2011;6(9):e24751.

37. Dvorak HF. Vascular permeability factor/vascular endothelial growth factor: a critical cytokine in tumor angiogenesis and a potential target for diagnosis and therapy. J Clin Oncol. 2002;20(21):4368-4380.

38. Lynn KD, Roland CL, Brekken RA. VEGF and pleiotrophin modulate the immune profile of breast cancer. Cancers (Basel). 2011;2(2): 970-988.
OncoTargets and Therapy

\section{Publish your work in this journal}

OncoTargets and Therapy is an international, peer-reviewed, open access journal focusing on the pathological basis of all cancers, potential targets for therapy and treatment protocols employed to improve the management of cancer patients. The journal also focuses on the impact of management programs and new therapeutic agents and

\section{Dovepress}

protocols on patient perspectives such as quality of life, adherence and satisfaction. The manuscript management system is completely online and includes a very quick and fair peer-review system, which is all easy to use. Visit http://www.dovepress.com/testimonials.php to read real quotes from published authors. 